\title{
LA NECESIDAD DE PACTOS DE ESTADO EN LA POLÍTICA ESPAÑOLA
}

\section{THE NEED FOR STATE AGREEMENTS IN SPANISH POLICY}

\section{Autor}

\section{Pedro Fernández Vicente}

Universidad Complutense Madrid (España)

pfdelavega@gmail.com

\section{RESUMEN}

La democracia en España está instalada desde 1977, en que se celebraron las primeras elecciones democráticas, en un sistema electoral útil en aquellos momentos en los que era necesario mantener un sistema capaz de fortalecer las estructuras democráticas con unos partidos fuertes que pudieran hacer frente a cualquier intención de volver a la dictadura. Una vez superada esa etapa no tiene sentido continuar con una ley electoral de listas cerradas y unos desequilibrios que priman a unas zonas y castiga a otras. Hacemos un repaso por los pactos que serían necesarios para crear bases más sólidas de las que tenemos en materias importantes como la educación, la sanidad, el sistema electoral o la lucha contra el terrorismo.

\section{PALABRAS CLAVE}

Democracia - Electoral - Sistema - Pacto - Sanidad - Educación 


\section{ABSTRACT}

Democracy in Spain has installed since 1977, which held its first democratic elections in an electoral system useful in those moments when it was necessary to maintain a system capable of strengthening democratic structures with a strong party that could meet any intention to return to dictatorship. Once that stage does not make sense to continue with a closed-list electoral law and some imbalances that prevail in some areas and punishes others. We review by the agreements would be necessary to create a more solid foundation from which we have on important matters such as education, health, electoral system and the fight against terrorism.

\section{KEY WORDS}

Democracy - Electoral system - Covenant - Health - Education

\section{ÍNDICE}

1. Antecedentes

2. Pacto antiterrorista

3. Pactos imposibles

4. Pacto para un nuevo Sistema electoral

5. Pacto por la Educación

6. Pacto por la Sanidad

7. Copago

8. Conclusiones

9. Bibliografía

10. Hemerografía 


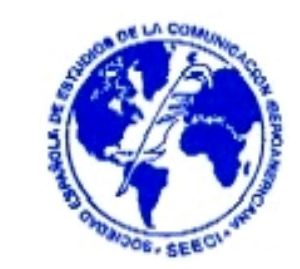

\section{Antecedentes}

El desarrollo de la actividad política a lo largo de los años que van desde la aprobación de la Constitución de 1978 hasta hoy está marcado por la vida parlamentaria. Como en toda democracia la representación parlamentaria tiene una incidencia capital en la vida ciudadana. El Congreso de los Diputados y el Senado se ponen, desde la entrada en vigor de la Constitución, al frente de las decisiones legislativas y del poder político de España. La representación resultante de las consultas electorales tiene dos constantes alternativas: o bien resulta una mayoría absoluta de alguno de los partidos que aspiran a gobernar o se quedan en esa mayoría suficiente, que se ha vendido denominando, y que permite gobernar con apoyos permanentes o puntuales, según las iniciativas legislativas que se presenten en cada momento. Son los pactos puntuales que han ido permitiendo la gobernabilidad del país con más o menos acierto.

Al margen de estos acuerdos ocasionales o de legislatura, los españoles demandan y España necesita, como garantía de estabilidad en la acción de gobierno que se reflejará en la vida cotidiana, una serie de Pactos de Estado que permitan el mantenimiento de determinadas estructuras más allá de la convocatoria electoral. Consenso entre quienes, potencialmente, puedan acceder al gobierno como compromiso de permanencia de esas leyes que deben mantenerse vigentes gobierne quien gobierne. Acuerdos de primera magnitud que dan estabilidad al país como la lucha antiterrorista, la sanidad, la educación...y otros que demandan los ciudadanos, como la ley electoral, que no siempre se llevan a cabo por intereses partidistas, por falta de diálogo u otros motivos menos confesables. El caso es que son los pactos que no llegan y que serían muy necesarios. De esos vamos a hablar aquí.

La segunda legislatura que gobernó el PP que empezó en el año 2000 y finalizó en el famoso 2004, en medio de la tragedia por los 191 muertos por las bombas en los trenes de cercanías, fue muy distinta de la primera. El PP accedió al gobierno en 1996 apoyado por CiU, el PNV y CC. 


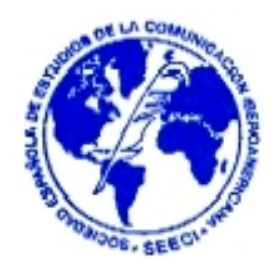

El acuerdo con CiU, que se denominó como pacto de Majéstic y que llevó a José María Aznar a la Moncloa como Presidente del Gobierno de España, sigue siendo un modelo en cuanto a lo que supuso de modernización para Cataluña, por las inversiones que se hicieron en aquella comunidad como consecuencia de un acuerdo que fue muy denostado durante años. Josep Antoni Durán i Lleida asegura, incluso, que el consenso entre CiU y PP hizo posible las obras de modernización y construcción del aeropuerto del Prat. Recuerda, el líder nacionalista, que aquella etapa fue la más positiva para la normalización del catalán y lo pone como ejemplo: desde aquel pacto, los jóvenes, no están obligados a hacer el servicio militar.

También hubo un acuerdo con el PNV. En el mes de Abril de 1996 se celebró una reunión en Madrid entre representantes del nacionalismo vasco y dirigentes del Partido Popular. A la reunión asistieron el Presidente del entonces Euzkadi Buru Batzar, Xabier Arzalluz e Iñaki Anasagasti, que entonces era el portavoz del Grupo Vasco en el Congreso. Representando al PP asistieron José María Aznar, como presidente que era del partido, acompañado por los tres máximos colaboradores en aquellos momentos: Rodrigo Rato, Jaime Mayor y Mariano Rajoy. La reunión se celebró sin presiones para las partes. En el momento de entrar en la sala donde se celebraba las conversaciones, el PP, no necesitaba que el PNV apoyase la investidura de J osé María Aznar para convertirse en Presidente del Gobierno pero el acuerdo con los representantes vascos en el Congreso de los Diputados le daba una estabilidad al ejecutivo entrante que, según el PP de aquella época, venía muy bien para ofrecer estabilidad a España.

Era la etapa del consenso, de las buenas relaciones entre el gobierno central del PP y los nacionalistas vascos y catalanes, relaciones que se deterioraron en los últimos compases de la legislatura y siempre por la diversidad de criterios de actuación con los denominados como partidos abertzales. El PP no aceptaba y sigue sin aceptar una mayor tolerancia con los grupos que mantienen una cierta benevolencia con los terroristas. El acercamiento de los presos etarras al País Vasco y la negativa del 
gobierno de José María Aznar a recibir a una comisión de los Derechos Humanos del Parlamento de Vitoria, que se había entrevistado previamente con Juan Lorenzo Lasa Michelena, alias Chiquierdi, supuso el comienzo de una etapa de enfrentamientos entre los dos grupos políticos que habían mantenido una proximidad. Incluso Iñaki Anasagasti anunció en aquellos dias el fin de las buenas formas con el gobierno del PP.

La ruptura del alto el fuego decretado por los terroristas en 1998 y el mantenimiento del Pacto de Estella entre el PNV, EA y HB, que consolidaba la independencia como precio político para alcanzar el fin de la violencia etarra y la utilización de las armas, fue el final de la armonía entre el PNV y el PP.

Las elecciones del año 2000 abrieron un nuevo panorama. El 12 de Marzo el PP alcanza la mayoría absoluta, 183 escaños frente a los 125 del PSOE, que provoca la dimisión de Joaquín Almunia.

En el mes de julio, recién estrenada la legislatura, llega a la Secretaría General del PSOE José Luis Rodríguez Zapatero y unos meses más tarde, a finales de año se firma el principio de un acuerdo entre los dos partidos mayoritarios, de cara a luchar contra el terrorismo etarra, el denominado como "acuerdo por las libertades y contra el terrorismo", más conocido como Pacto Antiterrorista.

Esa unidad confirma el fin de las buenas relaciones entre PP y PNV. Por otra parte el consenso alcanzado por el PP, en el gobierno, y el PSOE, en la oposición, se va conformando poco a poco como una herramienta útil en la lucha contra la violencia de ETA. 


\section{Pacto antiterrorista}

La sintonía de la lucha contra ETA se apoya en esas dos patas que son el PP y el PSOE, los dos partidos con representación nacional y con la posibilidad de gobernar en algún momento 0 , mejor dicho, los dos únicos partidos con entidad suficiente para tomar la iniciativa de formar gobierno aunque en muchas ocasiones, como estamos viendo a lo largo de los años, condicionado por el poder de los pequeños grupos nacionalistas con intereses muy definidos y localizados en sus respectivas comunidades autónomas.

El pacto conocerá en su dilatado camino momentos de incertidumbre e incluso inactividad, precisamente, por la influencia de esos grupos minoritarios que exigen, ahora al PP, ahora al PSOE, distanciarse del otro a cambio de apoyos parlamentarios. Exigencias que no siempre son bien entendidas por el partido que está en la oposición.

Si nos ceñimos a esta última etapa en la que el PSOE de José Luis Rodríguez Zapatero y el PP de José María Aznar, primero, y el de Mariano Rajoy, más tarde, llegaron a este acuerdo para aislar al terrorismo y su entorno, se produjeron diversas influencias negativas que marcaron periodos de debilidad del acuerdo antiterrorista. Uno de ellos fue el atentado del 11 de Marzo, del que hablaremos más tarde, cuando el PSOE acusó al PP de intentar utilizarlo electoralmente. Pero también influyó otra circunstancia, el compromiso de no pactar con el PP a cambio del acuerdo para formar gobierno en Cataluña con Pascual Maragall como President. Fue el denominado como Pacto de Tinell que nace como consecuencia del resultado de las elecciones en Cataluña el 16 de Noviembre de 2003. El ambiente no era el más apropiado para los acuerdos con el PP de José María Aznar instalado en la Moncloa sin contacto alguno con el sentir de la calle. Por otro lado Artur Mas sustituyó como candidato de CiU a la Generalitat a Jordi Pujol. El mensaje del nuevo líder nacionalista tampoco contribuyó en nada a aproximar posturas y radicalizó el 


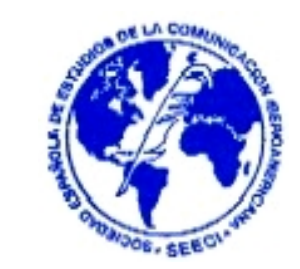

mensaje nacionalista con la idea de atraer los votos que las encuestas asignaban ya a ERC, liderada por J osep Lluis Carod Rovira y que se convirtió, por aquel tiempo, en un líder carismático que ocupaba la atención de los medios de comunicación. Rovira le robaba protagonismo y el liderato catalán que siempre había tenido sin discusión Jordi Pujol.

Tampoco José María Aznar desde la Presidencia del Gobierno central había colaborado mucho en bajar los ánimos nacionalistas con su postura radical y negativa de abrir un debate para el avance y expansión de la Comunidad Catalana.

En ese ambiente de cierta tensión y la aparición en escena de unos socios desconocidos hasta ese momento en la política nacional, como era ERC, se celebraban las elecciones en Cataluña. Los resultados no podían ser más desconcertantes y alejados de lo que podría ser la formación de un gobierno fuerte para la Generalitat. Tanto el PSC como CiU se quedaron muy lejos de poder formar un ejecutivo monocolor que les permitiese sacar su programa adelante. Ambos necesitaban apoyos. Los medios de comunicación especulaban sobre diferentes alternativas y siempre incómodas para los mayoritarios. Ni CiU con 46 diputados, ni el PSC con 42 podían aspirar a liderar una mayoría que necesitaba 68 escaños para gobernar con garantías.

En este ambiente de negociación continua para atraer una mayoría de izquierdas entre PSC, ERC y la coalición de ICV-EA, o formar una mayoría entre CiU y ERC, IOS socialistas se inclinaron por favorecer el ascenso de Pasqual Maragall a la Presidencia de la Generalitat, desbancando por primera vez a los nacionalistas catalanes del poder.

El acuerdo se denominó Pacto del Tinell que lleva el nombre del salón donde se firmó. Partido Socialista de Cataluña, Ezquerra Republicana de Cataluña e Iniciativa Cataluña Verdes-Ezquerra Alternativa formaron un gobierno de izquierdas al tiempo que se comprometían a no establecer ningún acuerdo de gobernabilidad con el PP ni 


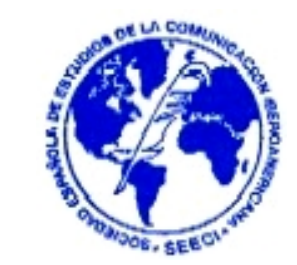

en Cataluña ni en el resto del Estado. El compromiso dejaba fuera de posibles acuerdos al PP con el gobierno o en el parlamento de la nación. Este anexo se hace más notorio a partir del 14 de Marzo de 2004 cuando el PSOE obtiene la mayoría necesaria en las elecciones generales y accede al poder.

El PP se ha quejado de este condicionante del Pacto de Tinell al que considera culpable permanentemente de la falta de diálogo entre el partido del gobierno y la oposición popular. Incluso se califico como cláusula antidemocrática por parte de los populares.

Fue un punto de partida poco recomendable para gobernar el país. El primer asalto de los independentistas fue el Pacto Antiterrorista que el partido del gobierno mantenía con el principal partido de la oposición. ERC pidió al Presidente del Gobierno la ruptura de ese acuerdo en intervenciones parlamentarias y en el debate de la comisión de investigación por los atentados del 11-M. La petición nunca fue atendida de manera explicita con la disculpa de los buenos resultados que se estaban obteniendo en la lucha contra el terrorismo. No obstante el entusiasmo del gobierno por hacer valer los principios que figuraban en el escrito del acuerdo se relajó durante algún tiempo. El pacto se vio abocado a un recorrido en el que tanto el PP como el PSOE se acusaron de querer romperlo con permanentes llamamientos de uno y otro para volver al entendimiento. No fue la primera legislatura de J osé Luis Rodríguez Zapatero su mejor momento. El consenso antiterrorista estuvo al borde de la ruptura y lo mismo sucedió con el resto de los pactos. Pronto se empezaron a ver los primeros síntomas de una ruptura entre los dos grandes partidos animada por los grupos parlamentarios que apoyaron la investidura para llevar a Rodríguez Zapatero a la Moncloa.

Aquí empieza una historia de desencuentros entre los dos principales partidos y únicos con capacidad de formar gobierno en el Estado. El distanciamiento se notó claramente durante los debates, primero, y en los acuerdos finales de la Comisión de 


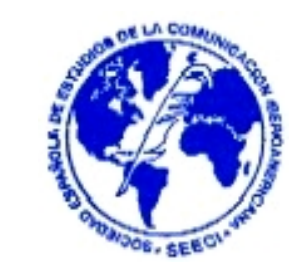

Investigación por los atentados del 11-M. que inició sus trabajos el 6 de Julio de 2004 y finalizó en Marzo de 2005. Se aprobaron las recomendaciones que se enviaron al gobierno para que adoptase la medidas necesarias en cuanto a la seguridad para evitar atentados similares en el futuro. Estas recomendaciones fueron apoyadas por todos los grupos parlamentarios excepto por el Grupo Popular que se abstuvo de participar en la votación. Con esta polémica entre el PP y el resto de los grupos parlamentarios se ponía fin a una investigación que no reconocían los populares y que como contestación a la firma del documento final, pedían nuevas comparecencias que fueron desestimadas.

Una vez finalizada la Comisión de Investigación por el atentado del 11 de Marzo, llegó el mes de Mayo de 2005 y con él el debate del Estado de la Nación. Después de dos días de debates sobre la situación en los que no faltaron referencias a cuestiones pasadas, el PSOE presentó una moción para solicitar al Congreso la autorización y el apoyo para negociar con ETA, en caso de que se produjera el abandono de las armas. La propuesta expresaba el apoyo a un posible proceso de diálogo entre los poderes del Estado y los violentos, siempre que se dieran las circunstancias para ello. También se considera un compromiso explícito que en ningún caso se trataría de negociar temas políticos porque la violencia, según aclaraban los socialistas, no tiene un precio político.

Esta decisión no le gusta al principal partido de la oposición. El PP considera que esta moción supone una amenaza para el pacto contra ETA, considera que el Congreso se rinde a la banda terrorista de la mano del ejecutivo. El editorial del ABC del 15 de Mayo hablaba de la derogación del pacto antiterrorista y la utilización de un lenguaje, por parte del gobierno y el PSOE, similar al de los nacionalistas al aceptar el alto del fuego como un acto voluntario de los terroristas y no como consecuencia de la acción de presión por parte de las fuerzas de Seguridad del Estado. "El Gobierno, decía el $A B C$, demuestra con esta moción que está abierto a la negociación. ETA ya dirá cual es su postura". Según el PP el terrorismo marca la 


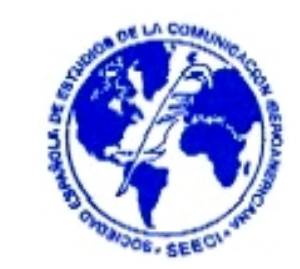

agenda de la negociación. Una decisión errónea, según el PP, que pronostica que la negociación será un fracaso.

Desde este momento hasta la ruptura de negociaciones que, según el gobierno se produjo después del atentado de la T-4, hubo altos y bajos en las relaciones entre el ejecutivo y la oposición. Según dicen Fernando Jáuregui y Manuel Ángel Menéndez en su libro, El Zapaterato, un periodo de escasa información por parte del Presidente del Gobierno al líder de la oposición. Esto y la sospecha de que las negociaciones con el entorno de la banda procedían de mucho antes, incluso antes de las elecciones generales, radicalizó la postura de Rajoy y endureció la oposición a todo lo que significaba negociación con Batasuna y ETA.

Finalmente la ruptura por parte de la banda terrorista empujó al Partido Socialista y al Presidente del Gobierno hacia las posturas más conservadoras mantenidas por el PP desde el principio. El pacto recuperó su estabilidad. Quedó un punto de sutura sin cerrar perfectamente y que se ha ido abriendo a medida que ha pasado el tiempo, como es el denominado caso Faisán. El Faisán es un bar en el que se reúnen simpatizantes abertzales. Un caso que sigue en manos judiciales porque durante la negociación del proceso de paz, una llamada telefónica desde una línea vinculada al Ministerio del Interior, alertaba a los presentes en el bar Faisán de una inminente redada policial. Un asunto, éste, que se ha ido configurando y tomando cuerpo a lo largo del tiempo pero que no impidió en su momento, ni ahora, que el pacto antiterrorista se mantenga en toda su extensión.

\section{Pactos imposibles}

Así, en principio, los pactos imposibles no existen pero se puede aplica tal denominación a esos de los que habla la calle, los ciudadanos en los lugares de trabajo, de ocio, o donde quiera que se junte un grupo de gente pero que nunca forman parte de las noticias como argumento político para llevar a cabo en un futuro 


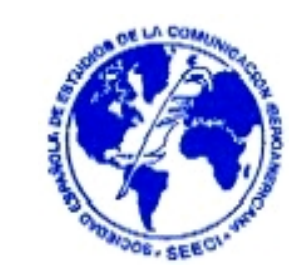

próximo o lejano. Es decir esos posibles pactos que a todos nos gustaría que se produjesen pero que nuestros representantes ni siquiera se lo plantean.

Como ejemplo son esas cuestiones que una cantidad inmensa, como dicen los políticos, de ciudadanos no entienden que nadie los ponga de duda. Uno de ellos es el sistema electoral, el pacto por la educación o el esperado y, posiblemente inevitable, pacto por la Sanidad.

Muchos ciudadanos pensamos también en un gran acuerdo de los partidos políticos para evitar la corrupción, que aleje las sospechas constantes de la financiación de los partidos políticos. Porque detrás de muchos enriquecimientos que aparecen en los medios de comunicación está el dinero que los partidos obtienen de forma inconfesable para hacer frente a esas campañas electorales que son muchas, demasiadas, y caras, muy caras.

Sería un pacto fundamental para mejorar la imagen de nuestros políticos que cada vez se deteriora más. De hecho en las encuestas que publica regularmente el CIS, el Centro de Investigaciones Sociológicas, la tercera preocupación es el comportamiento de los representantes. Dato escalofriante porque son ellos, los políticos, quienes deben ser garantes de la confianza de los ciudadanos para gobernar y manejar las cuentas del Estado, las cuentas de todos. Creo que este pacto debe ser objeto de un análisis único en otra ocasión

\section{Pacto para un nuevo Sistema electoral}

Después de tantos años de elecciones tras elecciones y de sobrevivir a nueve legislaturas en las que hemos visto como las minorías que representan a una sola comunidad autónoma han condicionado políticas de gobierno de interés nacional, no hay ni un solo votante que no se haga algunas preguntas sobre nuestro sistema electoral. Los políticos, los responsables de revisar las leyes que nos organizan a 


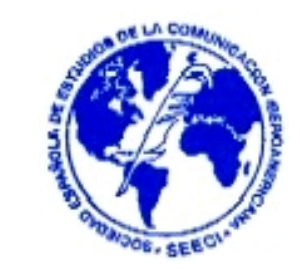

todos, parecen desconocer esas inquietudes ciudadanas o miran para otro lado cuando las posibles modificaciones saltan al primer plano del debate social. Qué duda cabe que nuestro sistema es democrático y libre. Eso no plantea un problema.

Pero cómo se puede considerar justa una representación en la que IU, por ejemplo, con más de novecientos mil votos obtiene dos escaños y el PNV, por utilizar otro ejemplo, alcanza seis con algo más de trescientos mil. Aceptamos lo de elecciones democráticas pero no aprobarían un examen de igualdad. Justo no es. Y la gente de la calle, la que vota, se pregunta el por qué de esta circunstancia, sin llegar a una conclusión convincente.

Se puede explicar técnicamente porque tal y como está planteado el sistema D'hondt se puede justificar matemáticamente, pero no soporta una explicación lógica. Sobre todo no se puede admitir que esté así desde hace cuarenta años, desde una perspectiva ciudadana. Sabemos que desde el punto de vista de las matemáticas no existe un sistema perfecto para el reparto proporcional de escaños y que el sistema D’hondt está vigente en otros países, no sólo en España, pero los responsables no hacen ni el más mínimo gesto por mejorar algo que es claramente injusto con algunos partidos y con algunas poblaciones, que necesitan más votos para conseguir los mismos representantes.

Y eso no es lo único que le ocurre a nuestro sistema electoral. El método de listas cerradas está muy bien para dar los primeros pasos, después de tantos años de dictadura y facilitar la creación de partidos políticos fuertes capaces de responder a las agresiones reaccionarias y conformar una vida cotidiana y callejera lo más libre y democrática posible. Hasta ahí no hay duda, pero más de treinta años después, ya es hora de modificar, de mejorar un sistema que desvirtúa totalmente la representación del parlamento. No sólo por lo que acabamos de mencionar, sino porque cuando los ciudadanos votamos en las elecciones generales, autonómicas 0 municipales, lo hacemos a unas listas cerradas. No podemos elegir a aquellos 


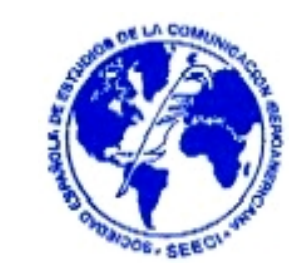

candidatos que nos resulten más interesantes o fiables. Estamos obligados a admitir y aceptar como buenos a todos los componentes de una lista en la que no hemos participado y en la que figuran un montón de nombres desconocidos, de los que ignoramos su pasado, su recorrido, no aportan fiabilidad y tampoco sabemos si tienen los suficientes conocimientos para llevar a cabo la labor para la que los estamos eligiendo. Todo un despropósito electoral que nos lleva una representación nada fiable, nada controlada por los votantes pero que proporciona un poder incalculable a los aparatos de los partidos. Este sistema electoral es positivo para aumentar el poder de los dirigentes encargados de confeccionar las listas que concurrirán en la fecha marcada. Esta circunstancia, además de tener efectos perversos sobre los trabajos individuales, además de premiar fidelidades no siempre confesables, además de excluir a quienes no escuchan la voz de su jefe, desvirtúa y empobrece el sistema democrático. Con el paso del tiempo los más críticos, los más creativos, los más demandados terminan encontrando otras actividades al margen de la política, los partidos y el reparto de puestos después de cada jornada electoral. Una fórmula que suele premiar a menudo a quienes han estado a la altura de las circunstancias apoyando y aplaudiendo al jefe allá donde lo ha necesitado. Qué duda cabe que sugiere dudas sobre el nivel democrático del sistema.

Las preguntas que se hacen los ciudadanos deberían tener, al menos, un reflejo en las inquietudes de los políticos que proponen en el corto plazo y desechan de sus planteamientos el futuro de la sociedad para la que dicen trabajar.

El voto a listas cerradas y la irregularidad del reparto de escaños es una cuestión frecuente en las tertulias de amigos, pero difícilmente se percibe en los ambientes de decisión. Es como si los gobernantes fueran por un lado y los pensamientos e inquietudes de las gentes fuesen por otro. La política desligada de la calle cada vez más. Se hacen propuestas sin tener en cuenta el interés general. 


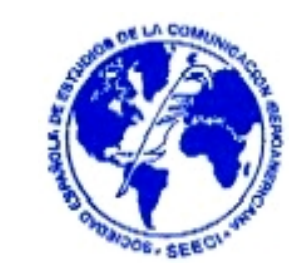

Aquí vuelve a surgir ese descontento con los políticos que han conseguido que los ciudadanos que les votan y los que se abstienen, todos juntos, consideren que representan el tercer problema para ellos, después del paro y la crisis económica. Personas desencantadas que discrepan en gran medida del gobierno y de la oposición en la misma proporción y, posiblemente, por los mismos motivos.

La ley electoral plantea algunas dudas incluida la representación a que da lugar. El Congreso de los diputados está ocupado en su mayoría por los dos grandes partidos que han gobernado alternativamente y el resto de los escaños, si exceptuamos a IU que tiene una representación exigua, son grupos nacionalistas con intereses tan locales que desfiguran el objetivo nacional que se le supone a la Cámara Baja. Además desvirtúa la representación estatal en beneficio de las comunidades autónomas, representadas por partidos nacionalistas. Grupos que con un puñado de votos, escaso, conforman minorías poderosas con intereses marcadamente localistas y desequilibrantes si los comparamos con las otras comunidades que no disfrutan de nacionalismos.

Motivos que invitan a una reflexión seria de los mayoritarios para iniciar los cambios que aconseja la experiencia. En estos años de democracia se han producido avances positivos para los intereses nacionalistas, pero rara vez, esos avances se han llevado a cabo si suponían alguna pequeña incomodidad para estos grupos minoritarios con influencias enormes, como es el caso de ERC en la octava legislatura que a cambio de votar la investidura de Zapatero dispusieron de múltiples privilegios difícilmente justificables a tenor del número de votos conseguidos en las urnas. Y lo mismo ha sucedido, sucede y sucederá con el PNV, CC, CiU o el BNG.

Datos que exigen, al menos, una reflexión conjunta. 


\section{Pacto por la Educación}

Otro pacto que sortean de forma permanente los responsables políticos es el de la educación. Los estudiantes y sobre todo los profesores necesitan un modelo estable y consolidado para transmitir en las mejores condiciones posibles la formación que necesitan los niños y los jóvenes de hoy, que ya tiene suficiente distorsión con la que provoca el progreso tecnológico y los desajustes que producen por el bajo conocimiento de una parte del profesorado, muchas veces inferior al de los propios alumnos.

No se puede decir que nuestro sistema educativo sea un modelo a tenor de los resultados que proporciona. Es preciso un pacto que ponga fin a tanta sucesión de siglas por las que atraviesa la educación en los últimos 25 años. Cada gobierno que entra nuevo quiere dejar su huella y elige a la educación para hacerlo. Una mala decisión.

Desde aquella LOECE ( Ley Orgánica del Estatuto de Centros Escolares) de 1980 con UCD en el poder y que fue la que cambió la cara a La Ley General de Educación y financiamiento de la reforma educativa de 1970, que entró en vigor en tiempo de la dictadura del General Franco. La LOECE, que mantuvo el sistema educativo de la ley anterior, regula el derecho a la educación al tiempo que abre la puerta a la participación de los padres y establece la tipología de los diferentes centros que habrá a partir de ahora. Como siempre sucede se hace sin la participación de la oposición y los socialistas anuncian su disconformidad con el texto aprobado.

Esto nos lleva a que cuando el PSOE arrasa en las elecciones generales de 1982 el modelo deja de ser útil y entra en un proceso de rectificación y adaptación de acuerdo a los nuevos tiempos que se viven en España. Una decisión apropiada en aquellos momentos en los que el país evoluciona de un gobierno, como fue el de UCD casi improvisado y apoyado por un partido desintegrado y que tuvo como 


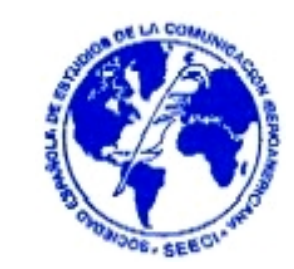

responsabilidad esencial convertir las instituciones que sustentaron a aquella dictadura en una Constitución que permitiera la llegada de un democracia, a otro apoyado masivamente en el Congreso y en la calle con capacidad y suficiente futuro para encarar una revisión general en todos los órdenes. En estas circunstancias, en las que se inicia un proceso de transformaciones, parece necesario y oportuno hacer lo propio con el sistema educativo. Son los primeros pasos de una democracia que necesita encontrar el sitio exacto en el que moverse en el futuro.

En este escenario llega el primer modelo auténticamente nacido en la democracia como es la LODE, la Ley Orgánica del Derecho a la Educación. Viene bajo el título de libertad de enseñanza y la creación de centros educativos. Además incorpora un concepto desconocido hasta el momento la participación. Se crea el Consejo Escolar y las Asociación de padres de alumnos, las APAS. No se trata de examinar aquí cada una de las leyes que se han cruzado en el camino de la educación ni de reflexionar sobre el contenido de cada una de ellas, que han sido varias, sino de criticar precisamente eso, los cambios que se han ido produciendo en nuestro modelo educativo.

Después de la LODE, en 1990, llegó una modificación más amplia con la LOGSE, Ley Orgánica General del Sistema Educativo, más ambiciosa que la anterior y que también fue criticada por la derecha. De ella se ha dicho que fue la aportación de la verdadera ideología del PSOE a la formación. Incorpora la educación obligatoria y común hasta los 16 años independientemente de la capacidad que pueda tener el alumno. Todos tienen que cursar una enseñanza básica hasta cumplir los 16 años.

Cinco años más tarde y lejos de un pacto de estado, tan necesario a estas alturas, se aprueba la LOPEG, la Ley Orgánica de Participación, Evaluación y Gobierno. Lógicamente reforma aspectos de la LOGSE porque busca consolidar la autonomía de los centros y la participación de todos los elementos que conforman la vida educativa. 


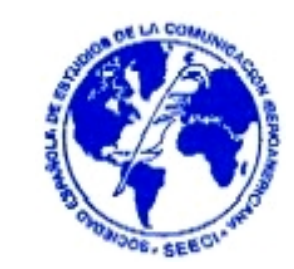

Esa distancia que hay entre los dos grandes partidos que pueden formar gobierno en distintos momentos de la historia y que evita la firma de un acuerdo que resuelva los problemas de interinidad que padece la educación en nuestro país, nos lleva a que en el 2002, con el PP en el poder, se ponga en marcha un nuevo texto bajo la siglas de LOCE, Ley Orgánica de Calidad de la Educación que debería haberse aplicado más allá de 2004 pero que no llegó a ejercer porque en Marzo de ese año el PSOE llegó al poder. La idea de este nuevo texto era alcanzar una calidad educativa para todos. Una de las innovaciones que introdujo fue la de romper la unidad de los niños: los de 0 a 3 años eran un grupo distinto a los alumnos de 3 a 6 años. La LOCE tenía en su horizonte elevar la consideración social de los profesores e incorporar los valores del esfuerzo y la exigencia personal.

Nunca se pusieron en marcha tales intenciones porque con el PSOE de nuevo en el poder, se paralizó la Ley de Calidad, aunque sin alternativa inmediata. Una decisión que no fue bien acogida por la comunidad educativa por la inseguridad y la incertidumbre que esta decisión generó en el cuerpo docente. No obstante se llevó a cabo la paralización y hubo que esperar hasta el 2006 cuando el partido en el poder aprobó la LOE que era una mezcla de todo lo anterior: LOGSE, LOPEG Y LOCE.

Esta, como las anteriores, recibe críticas desde distintos ángulos. Se dice que no soluciona el problema de la convivencia en los centros y que, de hecho, se ha deteriorado notablemente. También se crítica la falta de medidas para subsanar el bajo rendimiento y el abandono escolar de los jóvenes. Incorpora entre las asignaturas la discutida y criticada Educación para la Ciudadanía.

Como decíamos no se trata de analizar ni evaluar cada uno de los sistemas educativos que se han ido aprobando y que, al mismo tiempo, se han quedado obsoletos a juicio de los nuevos gobernantes, sino la de dejar testimonio del desacuerdo con la forma en que se lleva a cabo la organización de la educación. La sociedad quiere un consenso, al menos, entre los dos grandes partidos, esos que van 


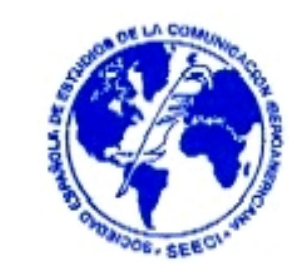

a gobernar en uno u otro momento. Un pacto capaz de instaurar un sistema educativo único que funcione y se desarrolle más allá de una legislatura y por encima de los distintos gobiernos que puedan llegar. Sólo así podremos obtener la suficiente experiencia e ir haciendo las modificaciones que el día a día nos vaya aconsejando sin protagonismos ni interferencias políticas de ningún signo.

El pacto por la educación tiene que adecuar la enseñanza, los profesores y los programas a los jóvenes de hoy y, sobre todo a los ciudadanos del futuro. Porque habría que hacerse una pregunta: ¿estamos preparando a nuestros jóvenes para la sociedad en la que van a tener que vivir y competir?

La educación afecta a toda la sociedad y no sólo en el presente. Educar es preparar el futuro. La sociedad del futuro insinúa unas características tecnológicas y unas condiciones de desarrollo que necesitan una preparación capaz de progresar por si misma. Quizá nunca antes nos hemos enfrentado a una generación que tiene la obligación de formar hombres y mujeres para gestionar recursos desconocidos, como sucede en estos momentos con la sociedad de la información. ¿Alguien se atreve a predecir la tecnología que necesitaremos manejar y conocer en los próximos quince o veinte años?, sin embargo tenemos la obligación de educar a quienes tendrán que afrontarla.

Es verdad que desde que se firmó la Constitución de 1978 son muchos los avances que se han ido acumulando en la educación Española con los diferentes gobiernos, pero los cambios y las variaciones que se han producido por la falta de un acuerdo global que supere en el tiempo las ideologías, ha impedido un avance mayor. 


\section{Pacto por la Sanidad}

Si hay una responsabilidad de estado que necesita la máxima atención esa es, sin duda, la Sanidad. Tal y como está el sistema es imposible mantenerlo. Las deudas son grandes e inciertas, lo que obliga a los responsables a dar los pasos necesarios para enriquecer unas arcas que, de no conseguirlo, nos situaría en una posición muy delicada y lejos del estado de bienestar.

Los gastos se incrementan de manera permanente y la financiación de todo el sistema de salud se hace imposible.

Después de las transferencias de 2001 la sanidad quedó bajo la responsabilidad de las comunidades autónomas, aunque vigilada por el Ministerio de Sanidad. Se trata del Sistema Nacional de Salud que declaró la sanidad como UNIVERSAL, GRATUITA Y DE CALIDAD.

La bonanza económica anterior permitía a las arcas del estado desviar fondos sobrantes a la financiación de unos gastos que se consideran sociales, como el que nos ocupa, pero la crisis nos sitúa en otro entorno distinto que precisa de fórmulas nuevas capaces de sacar adelante este sistema de salud que, hoy por hoy, no tiene la capacidad necesaria para satisfacer sus deudas. Una falta de recursos que nos sitúa en la encrucijada de qué hacer para mantener y mejorar la sanidad pública.

Lo que sabemos a estas alturas es que mantener el sistema a la última en todo es muy caro y no todas las comunidades están dando el mismo servicio ni de la misma calidad.

La Comisión Europea ha señalado a España como uno de los países que merecen estar en el grupo de los de "alto riesgo", de los que no son capaces de mantener las cuentas públicas por culpa del actual sistema de pensiones y del gasto sanitario. 


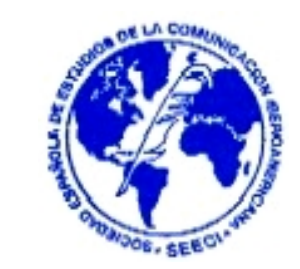

Porque no se trata únicamente de mantener. La tecnología, los nuevos medicamentos, los tratamientos modernos, el aumento de población y la mejora de nuestro sector sanitario, nos indica que el camino debe seguir por el sendero de la mejora y no solo por el mantenimiento. Y ese desarrollo, investigación e innovación necesitarán, inevitablemente, una mayor dotación económica. Pero ¿qué hacer para obtener mayores ingresos? Ese es el gran argumento que demanda la sociedad al tiempo que pide un Pacto de Estado que nos saque de esta incertidumbre en la que estamos desde hace algunos años. Un acuerdo que comprometa a todos los partidos, sindicatos, comunidades autónomas y amplios sectores de la sanidad. Un acuerdo que permita remar a todos en el mismo sentido.

España tiene un buen Sistema Nacional de Salud, si nos fijamos en los resultados de nuestra sanidad y en la cobertura, superior a muchos de los países de nuestro entorno. Pero esa misma amplitud le hace más frágil que otros más restrictivos. Esa debilidad obliga a que todos hagamos un esfuerzo para ayudar a mantenerlo. Hace falta un compromiso real entre los responsables públicos, los profesionales, la industria e incluso de los pacientes. Todos tenemos que ponernos de acuerdo si queremos salvar las dificultades que tenemos y que se presentarán en un futuro inmediato.

Un gran acuerdo que incluya entre sus compromisos la exigencia de ciertas responsabilidades de la administración, de cara a incorporar las nuevas tecnologías imprescindibles para mejorar constantemente y reflexionar sobre las modificaciones necesarias en la organización sanitaria, como el acceso a las urgencias, la educación y formación de los propios ciudadanos con la idea de exigir la necesidad de acudir a los médicos ordinarios y dejar las urgencias para los casos concretos en que lo son. De lo contrario, las auténticas necesidades de una atención rápida y las susceptibles de necesitarlo, quedan oscurecidas por la masa que se da cita cotidiana en las salas de espera de los grandes centros sanitarios para recibir atención inmediata. Es preciso, asimismo, utilizar adecuadamente los hospitales y los quirófanos para asistir 
a los procesos agudos y derivar las afecciones crónicas a otros lugares de atención como residencias o puntos especializados. Esto y la cirugía ambulatoria, cada vez más presente en nuestra sanidad, tendrá un efecto clarificador que desahogará la demanda de una sanidad oportuna y adecuada al tiempo en que se necesita la atención. Es una forma de acabar con las listas de espera. Pero todo esto pasa por la educación de la población para responsabilizar al usuario de la importancia de hacer un uso adecuado de la oferta de salud. Sin esa sunción de responsabilidad, el gasto, irá en aumento de tal manera que llegará a ser descontrolado.

\section{Copago}

El Copago es un término que alguien incluyó en alguna de sus propuesta y ha trascendido como concepto. El Copago puede tener muchas vías de aplicación. ¿Qué es y a qué se aplica el copago? ¿Qué porcentaje y a qué actividad se aplica el copago?. Hay muchas circunstancias por determinar.

Este Sistema que implica que los ciudadanos financien un porcentaje del Sistema Nacional de Salud, deberá ser acordado de forma global por todas las comunidades autónomas. Ninguna de ellas podrá aplicar una fórmula como el copago a título individual.

Antes de poner en marcha una fórmula como esta que despertará, sin duda, una cierta alarma social, es necesario diseñar las condiciones en que se abordará tal medida que pasa, necesariamente, por explicar a los ciudadanos detalladamente la situación real de la sanidad y de las pensiones, las posibilidades de mejorar la financiación y los riesgos reales si no se rectifican los comportamientos actuales. Es preciso dar a conocer todos los detalles sin esconder nada. La ciudadanía española es suficientemente madura como para entender el punto de partida y las actuaciones necesarias para mantener un sistema imprescindible para la sociedad, como es la sanidad y el sistema de pensiones. 
Una de las fórmulas posibles del Copago, como sistema disuasorio, se podría aplicar a las urgencias. Pero también a los medicamentos, a las visitas especializadas 0 simplemente a las consultas del médico de familia.

Como decía, el copago, si es que se lleva a cabo alguna vez, necesita una reflexión general de las comunidades autónomas y siempre dentro del Consejo Interterritorial para aplicarlo de igual manera en todo el Estado.

Pero, se haga como se haga, El Sistema Nacional de Salud, necesita un amplio compromiso de todos con el futuro de la sanidad pública y no sólo de los partidos políticos, sino también de las comunidades autónomas. En España hay ya un consenso más amplio de lo que se creen. Según el Consejero de Sanidad de la Comunidad de Madrid, Juan José Güemes, es mucho más lo que une que lo que separa. Ese es un buen principio.

\section{Conclusiones}

Los españoles demandan y España necesita, como garantía de estabilidad en la acción de gobierno que se reflejará en la vida cotidiana, una serie de Pactos de Estado que permitan el mantenimiento de determinadas estructuras más allá de la convocatoria electoral. Consenso entre quienes, potencialmente, puedan acceder al gobierno como compromiso de permanencia de esas leyes que deben mantenerse vigentes gobierne quien gobierne. Acuerdos de primera magnitud que dan estabilidad al país como la lucha antiterrorista, la sanidad, la educación...y otros que demandan los ciudadanos, como la ley electoral, que no siempre se llevan a cabo por intereses partidistas, por falta de diálogo u otros motivos menos confesables. 


\section{Bibliografía}

TORRES LÓPEZ, J. (2005): "Pactos de estabilidad y Estado de Bienestar: una nota sobre su dudosa compatibilidad" en Revista Quaderns de Política Económica, № 9.

EGUREN, N. (2007): "Situación actual de los pactos sustentadores del Estado de Bienestar. La sociología y los nuevos retos" en IV Congreso Astur-Galaico de Sociología.

SABIO, A. (2002): "25 años de los Pactos de la Moncloa" en Revista Trébede. Mensual aragonés de análisis, ㄲo 70.

SALA, J. M. (1994): "Estado de autonomías y convención constitucional: el papel de los denominados pactos autonómicos" en Revista REGAP, № 6.

\section{Hemerografía}

Informaciones publicadas en los diarios:

- El País

- $A B C$

- Público

- El Mundo 